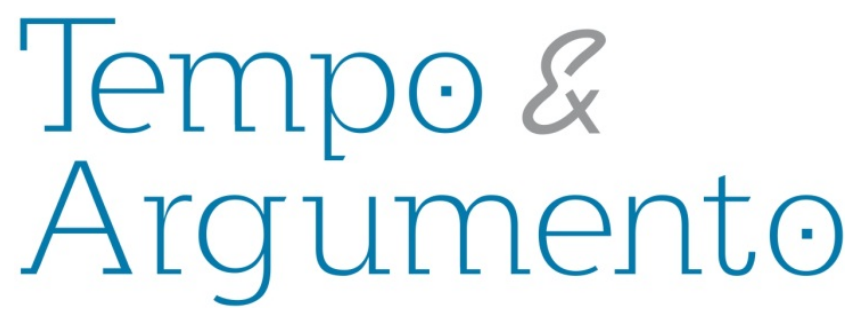

\title{
Memória, património educativo e espaços virtuais de aprendizagem. Uma experiência na Universidade de Granada
}

\begin{abstract}
Resumo
Este artigo apresenta uma experiência didática efetuada no contexto de um Projeto de Inovação Docente, onde se configurou uma Página da Internet, Património, Sociedade e Educação, como ambiente virtual de aprendizagem, tendo em vista contribuir para a recuperação do património históricoeducativo. $O$ património considerando as contribuições de Martí Úbeda, C. (2009), UNESCO (2012), Viñao, A. (2010), Moreno Martínez, P. L. (2009), assim como pelo aval das Sociedades Científicas do Património Histórico-Educativo é algo valioso, que se deve conservar e difundir na medida em que faz parte da memória e contribui para a construção de identidades numa comunidade. $\mathrm{Na}$ Universidade, a recuperação do património é trabalhada a partir da área educativa e sociocultural, propiciando ambientes e experiências de aprendizagem que incidem na recuperação do património que faz parte da memória coletiva. Proporcionamos uma série de atividades desenvolvidas pelos alunos no quadro do projeto, que são úteis para contribuírem para a análise, recuperação e reconstrução do património histórico, sociocultural e educativo. Este ambiente virtual possibilita a criação de conhecimento colaborativo e a abertura de outros horizontes que estimulem os processos de ensino-aprendizagem e a investigação sobre o assunto.
\end{abstract}

Palavras-chave: Educação; Inovação Docente; Património Histórico-Educativo; Conhecimento Colaborativo; Espaço Virtual de Aprendizagem.

\author{
Magdalena Jiménez-Ramírez \\ Doutora pela Universidad de Granada. Professora \\ do departamento de Pedagogia da Universidad \\ de Granada. \\ Espanha \\ madji@ugr.es
}

\author{
Para citar este artigo: \\ JIMÉNEZ-RAMÍREZ, Magdalena; DEL POZO SERRANO, Francisco José. Memória, património \\ educativo e espaços virtuais de aprendizagem. Uma experiência na Universidade de Granada. \\ Revista Tempo e Argumento, Florianópolis, v. 8, n. 19, p. 34 - 59. set./dez. 2016.
}

DOI: $10.5965 / 2175180308192016034$

http://dx.doi.org/10.5965/2175180308192016034 


\title{
Memory, educational heritage and virtual learning spaces: An experience at the University of Granada
}

\begin{abstract}
This paper presents a teaching experience undertaken in the context of a teaching innovation project, in which a website on heritage, society and education was prepared as a virtual learning environment, with a view to contributing towards the recovery of the historical educational heritage. In view of the work done by Martí Úbeda, C. (2009), UNESCO (2012), Viñao, A. (2010) and Moreno Martínez, P. L. (2009), and the support given by the historical education scientific societies, heritage is of considerable value in terms of conservation and dissemination, inasmuch as it shapes part of our memory and helps build identities within a community. At universities, heritage recovery is addressed from an educational and sociocultural approach, fostering learning environments and experiences that impact on the recovery of the heritage that makes up part of the collective memory. . We provide a set of activities developed by the students under the Project, which are of use when it comes to analysing, recovering and reconstructing the historical, sociocultural and educational heritage. This virtual environment makes it possible for collaborative knowledge to be generated, opening up new horizons to stimulate teaching and learning processes and further research in this field.
\end{abstract}

Keywords: Education; Innovative Teaching; Historical Educational Heritage; Collaborative Knowledge; Virtual Learning Space. 


\section{Introdução}

Este artigo apresenta uma experiência didática desenvolvida a partir de um Projeto de Inovação Docente - de agora em diante, PID - cuja finalidade consistiu em contribuir, a partir das aulas universitárias, para a recuperação do património educativo e sócio-histórico'. Com as matérias os alunos foram sensibilizados para a importância da recuperação de vestígios do passado para a sua conservação, análise e estudo críticoreflexivo. As atividades desenvolvidas no quadro do projeto foram a base para a configuração de uma Página da Internet como ambiente virtual de aprendizagem do património educativo e sociocultural, que contribui para ligar o ensino, a partir de enfoques histórico-educativos, às potencialidades que, mediante eventuais aplicações didáticas, são criadas pelo património difundido através da Internet (MARTí ÚBEDA, 2009).

Antes da apresentação da experiência de inovação docente criada, é pertinente que se justifique porque é que a recuperação do património é relevante, que se delimite o que é que se entende com o conceito e se mostrem os novos cenários que os recursos tecnológicos e a Internet oferecem para a recuperação e o estudo do património, em contextos universitários que reconfiguraram os espaços e os meios utilizados nos processos de ensino-aprendizagem, em conformidade com as diretrizes europeias para a Educação Superior.

Descreve-se em seguida a prática de inovação docente coordenada a partir da Universidade de Granada, onde se apresenta uma experiência didática sobre a recuperação do património e o estudo histórico da educação escolar e social, a partir de diferentes matérias. Foi criada uma Página Web, denominada Educação, Património e Sociedade (http://www.ugr.es/ patrimonioeducativo/index.php), tendo em vista avançar a partir da Universidade na recuperação e a construção de uma educação patrimonial que contribua para a conservação e difusão do património educativo a partir de ambientes

\footnotetext{
${ }^{1}$ Este trabalho insere-se no Projeto Educação, património e sociedade. Construção de um espaço virtual de aprendizagem dos alunos da Universidade de Granada (código 13-160), avaliado positivamente pela Agência Nacional de Avaliação da Qualidade (ANECA) e financiado pelo Vice-reitorado de Ordenação Académica da Universidade de Granada para o seu desenvolvimento durante dois cursos académicos, no âmbito do Programa de Inovação e Boas Práticas Docentes da convocatória de 2013, cuja conclusão se verificou no ano de 2015 .
} 
virtuais (Álvarez Domínguez, P., 2011). Os recursos tecnológicos possibilitam a (re)construção do conhecimento sobre o legado histórico-educativo, a consciencialização para a importância do mesmo e o forjamento de conceções do passado da educação no presente. A Página Web foi criada com os trabalhos efetuados pelos alunos sobre a temática do PID. Finalmente, a secção de conclusões explicita os aspetos mais significativos proporcionados pela inovação docente, pelas virtualidades oferecidas pelos recursos tecnológicos para a recuperação do património, assim como pelas prospeções de futuro.

\section{Recuperação do património: tecnologias, Internet e didática}

O estudo do património histórico educativo é uma tendência historiográfica de atenção crescente nas Universidades, que enriquece as perspetivas a partir das quais os investigadores desenvolvem o estudo do passado dos fenómenos educativos. Esta parcela de estudo inovadora está a evoluir por diversas vias: como temática de análise em encontros científicos (Colóquios, Jornadas, Congressos²); faz parte de artigos de investigação publicados, com a tendência para a especialização de revistas sobre património histórico educativo³; enfatiza-se a sua relevância mediante a constituição de sociedades científicas para a promoção destes estudos ${ }^{4}$; e promovem-se investigações financiadas em convocatórias públicas (MORENO MARTÍNEZ, 2009).

Estas iniciativas desenvolvem políticas e diretivas no âmbito dos quadros globais de educação, cultura e património vinculados à UNESCO (UNESCO, 2012) ou outros organismos internacionais, tendo em vista proteger, difundir e reconstruir a história da educação e o seu impacto pedagógico e social contemporâneo; assim como promover a educação vinculada à história cultural, em geral, onde o museu e o património se podem

\footnotetext{
${ }^{2}$ Em Moreno Martínez, P.L. (2009) é possível consultar uma descrição destes eventos científicos. O último a ser desenvolvido foi o das VII Jornadas Científicas da SEPHE e V Simpósio Ibero-americano, História, educação e património educativo, realizado em Donostia-San Sebastián, de 29 de junho a 1 de julho de 2016, http://sephe2016.congressus.es/historicoeducativo

${ }^{3}$ Veja a Revista Cabás, revista digital especializada no património histórico-educativo, editada pelo CRIEME (Centro de Recursos, Interpretação e Estudos da Escola) da Cantábria, http://revista.muesca.es/

${ }^{4}$ Por exemplo, a Sociedade Espanhola para o Estudo do Património Histórico Educativo (SEPHE), http://institucional.us.es/paginasephe/
} 
Este impulso experimentado a partir das diferentes iniciativas implicou que, a nível académico, a recuperação e difusão do património, de que a memória faz parte, passasse a ser um assunto de atualidade (VIÑAO, 2010). O conceito de património passou a ter diferentes significados, que fazem referência ao termo "bem", como "objeto ou conjunto de objetos valiosos para a sociedade do presente" (MARTí ÚBEDA, 2009, p. 11). É considerado como algo "que se herda ou constrói; simultaneamente é algo que se considera como próprio, no sentido de que faz parte daquilo de que se é proprietário" (VIÑAO, 2010, p. 19). Não é algo acabado, mas exige "consciência" ou "sentimento" de pertença e implica que algo é valioso para ser conservado e protegido por parte das pessoas e dos grupos sociais. Por isso, a conceitualização do património está em processo de construção e reconstrução, fruto da evolução experimentada pelo conceito (MORENO MARTÍNEZ, 2009; VIÑAO, 2010, p. 147).

De acordo com Moreno Martínez, P.L. (2009), o património educativo tem um

[...] valor histórico, como fonte para o conhecimento do passado, ao mesmo tempo que um poder evocador, que favorece a emergência da memória individual e coletiva, contribuindo para propiciar a construção de identidades partilhadas. Tanto pela sua condição de fonte histórica como pela sua capacidade para estimular a lembrança pessoal e social, merece e requer, simultaneamente, que seja preservado, assim como difundido e colocado ao serviço da comunidade

A partir da comunidade universitária, os professores estão cada vez mais sensibilizados para desenvolverem ações investigativas e docentes relacionadas com a recuperação do património. Em consequência disso, uma das linhas de investigação com uma certa trajetória no estudo do património é a dos museus pedagógicos (SUÁREZ; CALAF SAN FABIÁN, 2014), também denominada museologia da educação (YANES CABRERA, 2007a; MORENO MARTÍNEZ,2009; CARREÑO, 2007) ou museografia da escola (ESCOLANO, 2009), onde se compilam os bens patrimoniais, localizando-os em espaços físicos. 
É por isso que foram desenvolvidos alguns museus pedagógicos interessantes a nível internacional e ibero-americano (vinculados alguns dos casos às Faculdades de Educação e/ou Universidades). Apresentamos em seguida três tabelas com a distribuição por países e regiões do mundo. Pode-se ver que, no caso europeu, alguns dos mais numerosos estão na Espanha e na Alemanha, ou Turquia, país euroasiático. É interessante que se destaquem os quatro países da região latino-americana que apresentam museus relevantes em termos de pedagogia e educação (Venezuela, Colômbia, Chile e Brasil).

Tabela 1: Museus Pedagógicos na América Latina, Ásia e Oceânia.

\begin{tabular}{|lcc|}
\hline \multicolumn{2}{|c|}{ AMÉRICA LATINA } & \\
\hline Museu Pedagógico & Colômbia & Táchira, Venezuela \\
\hline Museu Pedagógico Colombiano & Chile & Bogotá, Colômbia \\
\hline Museu da Educação Gabriela Mistral & Brasil & Santiago do Chile, Chile \\
\hline Museu Histórico e Pedagógico Prudente de Moraes & Piracicaba, Brasil \\
\hline Australian Nacional Museum of Education & ÁSIA E OCEÂNIA & Tóquio, Japão \\
\hline Museu do património educativo da Universidade Tamagawa & Armidale, Austrália \\
\hline
\end{tabular}

Fonte: Elaboração própria a partir do IDEP (s/f., a).

Tabela 2: Museus Pedagógicos na Espanha.

\begin{tabular}{|ll|}
\hline \multicolumn{1}{|c|}{ ESPANHA } \\
\hline Museu Pedagógico Andaluz & Sevilha, Espanha \\
$\begin{array}{l}\text { Museu da Criança e Centro de Documentação Histórica } \\
\text { da Escola }\end{array}$ & $\begin{array}{l}\text { Albacete, Castela-La Mancha, } \\
\text { Espanha }\end{array}$ \\
\hline
\end{tabular}




\begin{tabular}{|c|c|}
\hline $\begin{array}{l}\text { Museu Laboratório de História da Educação "Manuel } \\
\text { Bartolomé Cossío" }\end{array}$ & Madrid, Espanha \\
\hline Museu Pedagógico de Arte Infantil & Madrid, Espanha \\
\hline Museu de Educação Ambiental San Pedro & Pamplona, Espanha \\
\hline $\begin{array}{l}\text { Museo Pedagóxico de Galicia (Museu pedagógico da } \\
\text { Galiza) }\end{array}$ & Galiza, Espanha \\
\hline $\begin{array}{l}\text { Arxiu y Museu de l'Educació de les Illes Baleares (Museu } \\
\text { de Educação das Ilhas Baleares) }\end{array}$ & Ilhas Baleares, Espanha \\
\hline $\begin{array}{l}\text { Centro de Recursos e Interpretação de Estudos da } \\
\text { Escola }\end{array}$ & Polanco, Espanha \\
\hline Museu Pedagógico Jesús Asensi & Madrid, Espanha \\
\hline Museu da Educação da Universidade de La Laguna & La Laguna, Espanha \\
\hline Museu Pedagógico Universidade de Salamanca & Salamanca, Espanha \\
\hline Museu pedagógico da Universidade de Huelva & Huelva, Espanha \\
\hline Centro Internacional da Cultura Escolar & $\begin{array}{l}\text { Berlanga de Duero, Soria, } \\
\text { Espanha }\end{array}$ \\
\hline Museu da Escola Rural das Astúrias & Viñao, Espanha \\
\hline
\end{tabular}

Fonte: Elaboração própria a partir do IDEP (s/f., a).

Tabela 3: Museus Pedagógicos na Europa.

\begin{tabular}{|c|c|}
\hline \multicolumn{2}{|l|}{ EUROPA } \\
\hline \multicolumn{2}{|l|}{ Turquia } \\
\hline Museu da Educação & Ancara, Turquia \\
\hline Museu da Educação Técnica de Meninas & Ancara, Turquia \\
\hline $\begin{array}{l}\text { Museu da Educação Profissional da Faculdade da Universidade de } \\
\text { Gazi }\end{array}$ & Ancara, Turquia \\
\hline \multicolumn{2}{|l|}{ Itália } \\
\hline Museo dell'Educazione & Pádua, Itália \\
\hline \multicolumn{2}{|l|}{ França } \\
\hline $\begin{array}{l}\text { Centre National de Documentation Pedagogique - Musée } \\
\text { National de L'Education }\end{array}$ & França \\
\hline \multicolumn{2}{|l|}{ República Checa } \\
\hline Komensky Pedagogical Museum & Praga, República Checa \\
\hline \multicolumn{2}{|l|}{ Sérvia } \\
\hline Pedagoški muzej (Museu Pedagógico) & Belgrado, Sérvia \\
\hline
\end{tabular}


Schulmuseum Mühlebach

Amriswil, Suíça

\section{Ucrânia}

\begin{tabular}{|c|c|}
\hline Museu Pedagógico da Ucrânia & Kiev, Ucrânia \\
\hline \multicolumn{2}{|l|}{ Suíça } \\
\hline Schulmuseum Mühlebach & Amriswil, Suíça \\
\hline \multicolumn{2}{|l|}{ Alemanha } \\
\hline $\begin{array}{l}\text { Schulmusem-Werkstatt für Schulgeschichte (Museu e } \\
\text { Laboratório de História da Escola) }\end{array}$ & Leipzig, Alemanha \\
\hline Schulmuseum der Universität Erlangen-Nuremberga & Nuremberga, Alemanha \\
\hline $\begin{array}{l}\text { Saarländisches Schulmuseum Ottweiler - (Fundação } \\
\text { Museu Escola do Território do Sarre) }\end{array}$ & Ottweiler, Alemanha \\
\hline Pädagogisches Museum & Bielfeld, Alemanha \\
\hline Hamburger Schulmuseum & Hamburgo, Alemanha \\
\hline
\end{tabular}

Fonte: Elaboração própria a partir do IDEP (s/f., a).

Os museus pedagógicos funcionam como espaços e contextos alternativos à sala de aulas tradicional, onde os estudantes se deparam com outros tipos de relações mais horizontais nas possibilidades da aprendizagem (que transita por práticas interativas e autónomas, a partir de métodos de investigação sobre materiais pedagógicos que permitem um olhar contextual (sociocultural, cívico e crítico) da educação (CARIDE; POSE 2013). O museu pedagógico constitui um meio cultural onde o legado histórico da educação e da pedagogia se tornam património (desde materiais educativos múltiplos como os de sala de aulas ou os de laboratório, revistas educativas, cadernos, jogos infantis, livros, imagens, entre outros) como cenários de conservação da memória histórica, para se compreender e valorizar a renovação pedagógica, as diversas tradições educativas e os seus modelos pedagógicos, as culturas e instituições educativas e escolares ou as didáticas gerais e específicas aplicadas às diversas áreas do conhecimento ao longo da história e das diversas correntes internacionais, nacionais, regionais da educação, dado que existe presença universal das mesmas (com a principal ausência africana, conhecida pelo menos até à data), tal como se apresenta nas tabelas 1, 2 e 3.

Portanto, os propósitos educativos associados a estes museus podem ser variados, na linha do que foi assinalado acima de acordo com o contexto, mas também é 
relevante que se realce, ao nível da inovação docente, que estes meios educativos se podem apresentar a partir das diversas disciplinas, dos programas e atividades académicas ou sociais, para favorecerem processos e projetos centrados na exploração, nos centros de interesse dos estudantes ou na cooperação dos grupos que focalizem o “aprender fazendo" (DEWEY, 1960) ao trabalhar sobre assuntos educativos ou pedagocos principais, ao estilo do que é proposto por museus como o SchulmusemWerkstatt für Schulgeschichte (Museu e Laboratório de História da Escola), na Alemanha; ou o Museu Laboratório de História da Educação “Manuel Bartolomé Cossío” na Espanha. Estamos de acordo com Ramos, S. e Pericacho, F. J. (2015), quando afirmam que

\begin{abstract}
"Pensamos que o estudo, reflexão e redefinição deste processo histórico podem favorecer a construção de propostas e iniciativas futuras que continuem a (re)significar o sentido da renovação pedagógica, contribuindo por um lado para o aumento do quadro teórico de debate em toda a comunidade educativa sobre o sentido da educação e a finalidade da escola, face à necessidade cada vez mais urgente de uma nova cultura e contexto escolar que promovam nos estudantes a possibilidade de exercerem de forma dinâmica, crítica e integral o desenvolvimento de todas as suas capacidades e potencialidades, e não só a mera resposta mecânica a problemas desligados da realidade. E, por outro lado, impulsionando uma formação competente e sólida dos futuros educadores e docentes para enfrentarem os desafios e problemas sociais, culturais, económicos, ambientais, éticos, etc., que o século XXI impõe"( RAMOS; PERICACHO, 2015, p.69).
\end{abstract}

Estes espaços estão atualmente a ser reorientados para a gestação de museus virtuais $^{5}$, aproveitando as possibilidades que as tecnologias podem proporcionar para a configuração dos museus (RUIZ BERRIO, 2002). O impacto das tecnologias está a implicar alterações profundas no modo como se transmitem as informações e como se constrói o conhecimento, possibilitando também uma reconfiguração e reorientação dos procedimentos através dos quais se estuda, recupera e difunde o património. 0 património já não está localizado unicamente em espaços físicos, mas as oportunidades

\footnotetext{
${ }^{5}$ A título ilustrativo, indicamos alguns Museus Pedagógicos virtuais: o Museu Virtual de História da Educação (MUVHE) da Universidade de Múrcia, http://www.um.es/muvhe/user/; Museu da Educação, Memória viva do nosso ensino, da Universidade de La Laguna, http://museoedu.webs.ull.es/; o Museu Virtual da Escola, da Universidade Nacional de Luján (Argentina), http://www.unlu.edu.ar/ museo/contenidos/elaula/aula.htm; o Centro Virtual de Memória em Educação e Pedagogia de Bogotá (Colômbia), http://www.idep.edu.co/wp_centrovirtual/; ou o Museu da Educação Gabriela Mistral, http://www.museodelaeducacion.cl/648/w3-channel.html
} 
que a rede Internet oferece possibilitam uma alteração dos meios de apresentação, preservação e difusão do legado histórico-educativo do nosso passado pessoal e coletivo, através do uso de plataformas e espaços virtuais para a aprendizagem nos processos de ensino-aprendizagem.

Este conjunto patrimonial de objetos e de informação pode ser armazenado virtualmente, possibilitando o acesso através da Web, tendo em vista conhecer, analisar, interagir e fomentar a atividade mental, emocional e cognitiva dos participantes. A Internet é um meio que possibilita a formação, comunicação, pensamento e reflexão para se trabalhar didaticamente e se construírem novos conhecimentos. Esta modalidade virtual de conhecimento e difusão do património educativo e pedagógico está a possibilitar a reconstrução da memória histórico-social e histórico-cultural a partir da educação.

Neste sentido, os ambientes virtuais permitem a difusão de ficheiros e publicações digitais (por vezes com bibliotecas virtuais), a visualização de vídeos educativos ou a apresentação de notícias sobre o âmbito ${ }^{6}$. Estas plataformas, além disso, têm um grande valor de construção histórica a partir de fotografias históricas sobre o magistério ou os materiais educativos e escolares. Esta responsabilidade social das instituições educativas e universitárias apresenta, além do valor teórico, didático e curricular, um alto compromisso pelos aspetos ético e político da pedagogia com projeção de luzes que iluminam uma nova história da educação escrita a partir de baixo (BURKE 1999) por se aproximar às situações de vulnerabilidade humana vinculadas à área da educação.

Um bom exemplo disso é o Centro Virtual de Memória em Educação e Pedagogia, desenvolvido pelo Instituto para a investigação Educativa e o Desenvolvimento Pedagógico (IDEP) e o Museu Pedagógico Colombiano da Universidade Pedagógica Nacional (UPN). Por intermédio deste espaço, são oferecidas minicrónicas sobre situações de dificuldade social na Colômbia relativamente à relação de escola, famílias e sociedade, as intra-histórias de raparigas adolescentes em situação de gravidez ou alguns

\footnotetext{
${ }^{6} \mathrm{O}$ Centro de Investigação MANES é um Centro de Investigação interuniversitário, dedicado ao estudo histórico dos manuais escolares da Espanha, Portugal e América Latina, que oferece na sua Página da Internet (http://www.centromanes.orgl) bases de dados, bibliotecas virtuais, projetos de investigação, entre outros, que possibilitam a atividade de investigação e de recuperação e difusão do património na linha em que se tem vindo a argumentar.
} 
Portanto, as iniciativas da comunidade universitária para a recuperação do património está a ser difundida virtualmente, graças à criação de ambientes virtuais Open Access como os museus pedagógicos virtuais (Yañes Cabrera, C., 2007a, 2007b; Álvarez Domínguez, P., 2009), projetos de investigação desenvolvidos que vinculam recuperação do património e TIC's (AGULLÓ, PAYÀ, 2009; AGULLÓ, BASCUÑÁNPAYÀ, 2009) ou algumas experiências docentes universitárias (PAYÀ, e, 2012 ${ }^{7}$ ). Os recursos tecnológicos permitem a visualização, reflexão e consulta do material patrimonial recuperado, estimulam a investigação e prolongam, para além das margens temporárias e concetuais da matéria, os processos de aprendizagem, reconstrução e reflexão sobre o estudo do nosso passado; e possibilitam a divulgação do conhecimento.

Desta forma, a reorientação dos processos de ensino-aprendizagem é fundamental na Universidade, onde as dinâmicas de estudo requerem metodologias mais dinâmicas e ativas, que permitam a interação entre professores e alunos, introduzindo inovações educativas e aproveitando as potencialidades que as tecnologias e a Internet têm para a construção do conhecimento (ALBA PASTOR, 2005). Seguindo Álvarez Domínguez, P. (2009), o aspeto telemático e digital na sociedade da informação apresenta alterações nas formas de trabalhar, pensar, comunicar e estudar que exigem a "[... ] modificação de determinadas estratégias e procedimentos didáticos necessários para se aceder, construir e interiorizar o conhecimento científico, histórico e educativo" (ÁLVAREZ DOMÍNGUEZ, 2009p. 594). Estas alterações implicam a reestruturação das metodologias docentes para a criação de espaços de diálogo, debate e reflexão que consciencializem para a procura, seleção, análise e interpretação do património históricoeducativo.

No impulso de ações docentes nesta linha, na Universidade existem atuações educativas que incidem, a partir de uma perspetiva didática, na sensibilização para o fomento do estudo, da proteção-preservação e da divulgação do património sócio-

\footnotetext{
${ }^{7} \mathrm{Na}$ Web Património educativo. Um espaço virtual de aprendizagem para a didática do património educativo (http://www.patrimonioeducativo.es/) pode-se aceder à experiência docente universitária.
} 
histórico, educativo e cultural. Consideramos o património educativo como o que se cria e produz no interior das instituições educativas, que muitas vezes é complementado com objetos que provêm do exterior (VIÑAO, 2012) (documentos escritos, memórias escolares, diários, livros de texto, trabalhos de alunos, fotografias, imagens, áudios, arquivos orais, fontes iconográficas, exposições educativas, cartas, cadernos escolares, mobiliário escolar), que têm a ver com os sinais de identidade (VELASCO, 2007) do contexto e do trabalho educativo, referidos a uma "cultura institucional" e "história material" das instituições educativas e sociais (VIÑAO, 2010).

Para apoiarmos esta linha argumental, desenvolvemos uma ação docente que vincula o património socioeducativo e cultural às potencialidades que os ambientes virtuais oferecem, tendo em vista salvaguardá-lo e contribuir para a preservação da memória coletiva de um património que faz parte da memória dos que o tornaram possível, na medida em que identificamo-nos com a contribuição de Viñao, A. (2015, p. 1213),

[...] a história é feita a partir da memória individual, coletiva, social e institucional, da incorporada em todo o tipo de objetos e documentos e da depositada em determinados lugares e que, por sua vez, a escrita da história, a operação histórica, trabalha e (re)constrói tal memória. Que embora a história como atividade científico-investigadora não se identifique com a memória - nem esta com aquela -, não é possível fazer história a não ser a partir das(s) memória(s) e sem, simultaneamente, $\mathrm{a}(\mathrm{s})$ (re)construir, isto é, sem criar memória(s)

\section{Ambientes virtuais: espaços fundamentais para a difusão, estudo e recuperação do património.}

A experiência adquirida por um conjunto de professoras da Universidade de Granada na investigação ${ }^{8}$ e na docência, relacionada com a História da Educação e a didática do património educativo, permitiu a junção de ideias para se concorrer à

\footnotetext{
${ }^{8}$ Projeto denominado Construção de uma biblioteca virtual para a disciplina de História da Educação na Universidade de Granada, Ministério da Educação, 2006; concessão de uma Bolsa de Estudos de Iniciação à Investigação (2007) da Universidade de Granada para a construção uma Web de fontes e recursos para a História da Educação das mulheres (http://www.ugr.es/ fuenteshistoriaeducal), e um Projeto de Inovação Docente Reconstrução de vivências a partir da educação intergeracional: história oral, fontes iconográficas, reminiscências e outros recursos pedagógicos (código 08-124), Universidade de Granada, curso académico 2008-2009.
} 
convocatória de Projetos de Inovação Docente, na modalidade de inovação na gestão online dos processos de ensino-aprendizagem ${ }^{9}$, tendo em vista avançar na recuperação e construção de uma educação patrimonial que contribua para a conservação e difusão do património educativo a partir de ambientes virtuais (ÁLVAREZ DOMíNGUEZ, 2011). Os recursos tecnológicos possibilitam a (re)construção do conhecimento sobre o legado histórico-educativo, a consciencialização para a importância do mesmo e o forjamento de conceções do passado da educação no presente.

$\mathrm{Na}$ inovação docente os alunos participaram a partir das matérias envolvidas ${ }^{10}$ na recuperação de elementos culturais e históricos que lhes possibilitou a interpretação da vida das escolas e de outras instituições socioeducativas, assim como a análise dos conteúdos e atividades didáticas com uma perspetiva crítico-reflexiva. Esta ação é fundamental se considerarmos que, nos atuais planos de estudo das Universidades espanholas, os conteúdos histórico-educativos têm uma presença cada vez mais minoritária, obviando a importância da recuperação de elementos educativos, sociais e culturais, que fazem parte da nossa memória, como uma prática individual, coletiva e público-privada de um passado histórico-educativo e sociocultural que, a partir da História da Educação, se deve preservar (VIÑAO, 2003).

Os objetivos básicos apresentados para o PID foram tornar os alunos participantes no estudo e na recuperação do património, dotando-os de uma formação histórica, educativa e cultural; criar uma Página da Internet que apresente, para a sua divulgação e estudo, o património educativo, cultural e social recuperado através do trabalho académico, didático e pedagógico efetuado pelos alunos a partir das nossas matérias

\footnotetext{
9 Participação das professoras Dras. Madalena Jiménez (Coordenadora), Fanny Añaños, Socorro Entrena, Sonia Mota, Victoria Robles, pertencentes à Universidade de Granada e o Dr. Fco. José del Pozo, professor colaborador externo, atualmente adscrito à Universidade do Norte (Barranquilla, Colômbia). Também colaborou a doutoranda Da. María del Mar García Vita.

${ }^{10}$ Histórias do Sistema Educativo Espanhol e das suas Instituições, Pedagogia Social, Inclusão-exclusão socioescolar da Juventude (Licenciatura em Pedagogia, UGR); A escola na Educação Infantil: Políticas Educativas Comparadas da União Europeia (Licenciatura em Educação Infantil, UGR); Animação Sociocultural, Educação para a Igualdade entre Homens e Mulheres (Licenciatura em Educação Social, UGR); Movimentos de Mulheres no Mundo, Transformações socioeducativas na Espanha do Século XX (Mestrado de Estudos das Mulheres e de Género, GEMMA, UGR); Sistemas Lineares (Licenciatura em Engenharia de Tecnologias da Telecomunicação, UGR); Educação Social (Mestrado em Educação, UniNorte).
} 
docentes; colocar ao serviço da comunidade educativa e social um espaço virtual que contenha e crie experiências, atividades didático-educativas, reflexões e oportunidades; e sensibilizar para a recuperação, conservação, interpretação e valorização do património socioeducativo e cultural. Os ambientes virtuais de aprendizagem, simultaneamente, representam experiências didático-pedagógicas onde podem ser desenvolvidas competências de cidadania e interculturais, com a participação diversa dos alunos (CANO, JBARRETO, DEL POZO, 2016).

A Web Património, Educação e Sociedade está configurada como um espaço virtual de acesso aberto (Open Access), http://www.ugr.es/ patrimonioeducativo/index.php. Para a sua configuração, o PID contou com uma dotação orçamental mínima, que permitiu que se contratasse temporariamente um bolseiro-informático em estágio com os conhecimentos necessários para a gestão do ambiente virtual de aprendizagem. 0 bolseiro programou a Web, tendo em atenção as orientações que as professoras envolvidas no PID lhe fizeram, de tal forma que a Web tivesse uma lógica quanto à forma como se apresentavam os materiais trabalhados pelos alunos a partir das diferentes matérias.

Está estruturada numa secção introdutória Sobre o projeto, as Áreas de conhecimento, os Profissionais convidados, os Professores participantes, o desenvolvimento de Eventos, um espaço de Contacto e um Contador de visitas (Veja a imagem 1). Na docência, o uso de tecnologias baseadas na Internet e nas ferramentas Web permitem o aumento das aprendizagens de modo exponencial, sem limitação geográfica, contribuindo para a construção de redes de aprendizagem pessoal (Personal Learning Networks, PLN) (Schaffert, S. \& Hilzensauer, W., 2008). Nestas redes, as pessoas que se ligam entre si podem permutar e aprender, ocorrendo uma aprendizagem social que permite a retroalimentação, o encontro e a partilha de recursos para a formação, a obtenção de ideias e experiências de profissionais, a procura de soluções em colaboração e o acesso às informações. 
Memória, património educativo e espaços virtuais de aprendizagem. Uma experiência na Universidade de Granada

Magdalena Jiménez-Ramírez, Francisco José Del Pozo Serrano

Imagem 1.- Página da Internet Património, Educação e Sociedade.

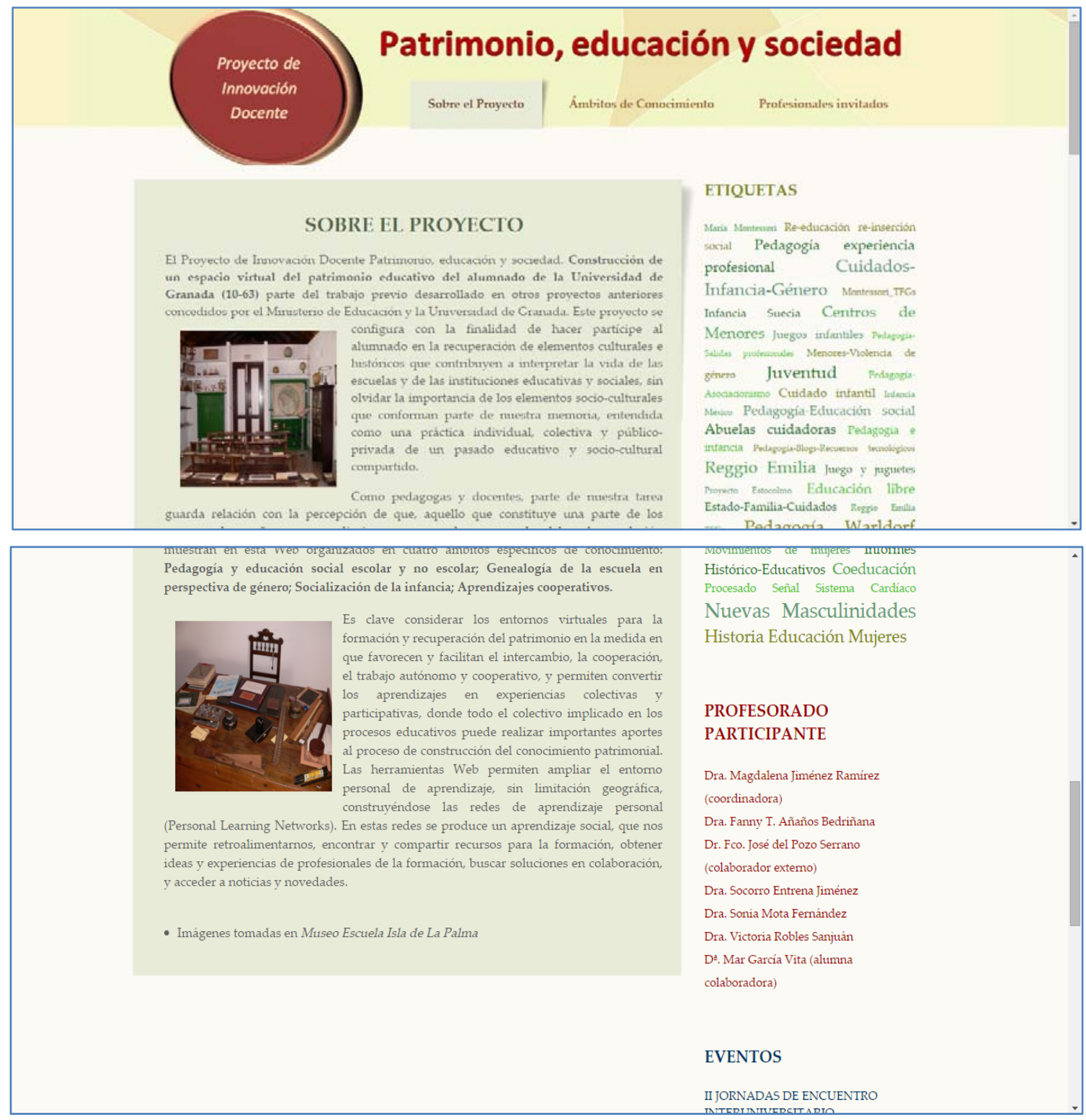

Visitas: 186

Reuniones de trabajo y asistencia a Congresos Contacto y comentarios

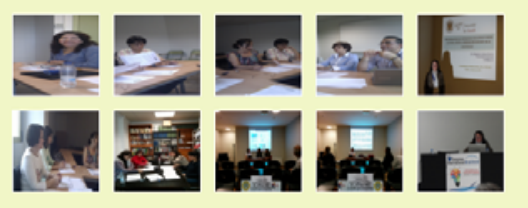

(d) Enviar un mensaje a la

Q para cualquier tipo de

Ademis, aqui pueden resuerencia.

Ademas, aquil pueden verse los

recibidos por bor wiantos.

$>$ Política de Privacidad

$>$ Accesibilidad

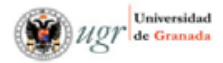

Esta página ha sido desarrollada gracias a la financiación obtenida en la convocatoria de 2013 del Programa de Innovación y Buenas Prácticas Docentes del Vicerrectorado de Ordenación Académica 
Os materiais resultantes mais significativos que foram produzidos localizaram-se em quatro secções, denominadas Áreas de conhecimento, que as professoras agruparam de acordo com as temáticas de trabalho e que estão relacionadas com as matérias envolvidas no projeto (Pedagogia e educação social escolar e não escolar; Aprendizagens cooperativas; Socialização da infância; Genealogia da escola em perspetiva de género), na secção Profissionais convidados para a aula e na secção Eventos. Embora o material didático esteja localizado nas respetivas Áreas de conhecimento, para se facilitar a procura foi criado um espaço denominado Etiquetas, que consiste em palavras-chave que permitem o acesso direto ao trabalho académico relacionado com o património realizado pelos alunos. Veja a imagem 2.

Imagem 2.- Áreas de conhecimento da Página da Internet Património, educação e sociedade.

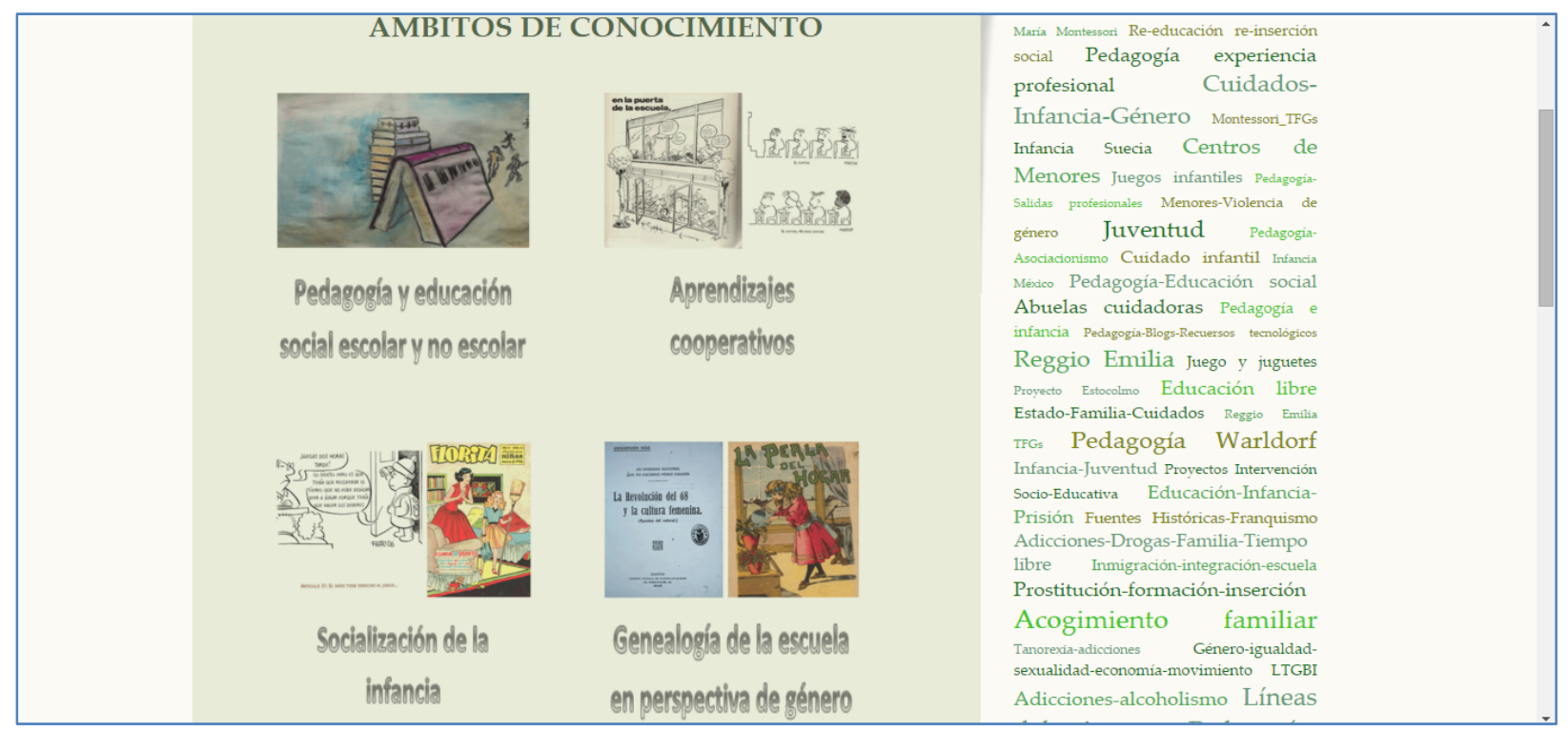

Desde o início da docência, explicamos aos alunos que a um conjunto de professoras tinha sido concedido um PID, cuja finalidade consistia em estudar e analisar a partir das nossas matérias atividades relacionadas com elementos históricos e patrimoniais. Apresentámos os programas das disciplinas e tornámos os alunos participantes para pensarem em eventuais ações e atividades que poderíamos desenvolver vinculadas com o objetivo do PID. A partir de cada matéria as propostas foram diferentes, embora relacionadas com a perspetiva histórica, educativa e 

atividades consensuais e programadas para a avaliação a partir de cada uma das matérias. Foram selecionados os trabalhos que satisfaziam os requisitos básicos de um trabalho académico: conhecimento de conteúdos, fundamentação e justificação dos mesmos, redação e clareza das ideias desenvolvidas; trabalhos estruturados a nível científico e argumentados com capacidade crítico-analítica; seguimento dos trabalhos individuais e em equipa; exposições, partilha e debate sobre os mesmos nas aulas universitárias.

A partir da Universidade esta implementação é fundamental para contribuir para a consciencialização dos alunos como futuros cidadãos na importância de participarem para conservarem o património histórico-educativo da nossa sociedade. 0 desenvolvimento de processos de ensino-aprendizagem, unidos à análise e estudo de elementos patrimoniais da escola, é fundamental para promovermos o conhecimento, interpretação, difusão e exposição da nossa própria história através da docência na universidade (ÁLVAREZ DOMÍNGUEZ, 2011).

Desde o primeiro ano do desenvolvimento da inovação no curso académico de 2013-2014, as professoras investigadoras participantes utilizaram o ambiente virtual como um espaço com recursos didáticos, a partir do qual se pode trabalhar academicamente com os alunos na recuperação do património histórico-educativo. Os alunos foram conhecedores do espaço virtual e metodologicamente utilizámo-lo na nossa docência, sendo motivador pelo facto de ser um espaço construído com as contribuições, previamente supervisionadas, dos alunos a partir das matérias, o que permitiu o desenvolvimento de processos de ensino-aprendizagem com o património (SUÁREZ, , CALAF, SAN FABIÁN, 2014). Apesar de ser uma experiência iniciada nas, e a partir das aulas universitárias, a Web Património, Educação e Sociedade pode ser um espaço partilhado por profissionais, tanto de outros níveis educativos como de outras áreas e ambientes socioculturais, e por alunos e investigadores que desenvolvam uma linha centrada na História e na educação patrimonial. Com efeito, aos alunos de cursos 
Esta Página da Internet deve ser entendida como um espaço que se irá transformando de acordo com o desenvolvimento das atividades didáticas promovidas a partir das matérias docentes. A experiência dos dois cursos académicos evidencia resultados positivos e um envolvimento dos alunos muito favorável ao desenvolvimento destas iniciativas porque, por um lado, as atividades elaboradas como parte dos seus próprios processos de aprendizagem constituem-se como um recurso básico na recuperação do património e, por outro, porque as fontes criadas estão acessíveis em ambientes virtuais de acesso livre, meio que costumam utilizar para a procura de informações, ao mesmo tempo que as fontes são de enorme valor para o estudo do nosso passado educativo (YANES CABRERA, 2007a). Pelo facto de ser uma Página Web open access, oferece a possibilidade de ser utilizada por parte de estudantes, profissionais, investigadores e historiadores interessados no assunto.

A proposta de recuperação do património mostra em linha uma série de recursos úteis para a docência e a investigação. As atividades propostas a partir das matérias, desenvolvidas pelos alunos como trabalhos propostos na aula, têm uma orientação formativa e histórica e concretizam-se em relatórios histórico-educativos de colégios segregados por sexo; ensaios sobre a construção da desigualdade de género, coeducação, feminismos e novas masculinidades; fontes históricas como fotos de centros escolares, imagens de quadros de professores, expedientes académicos, atestados médicos, imagens de manuais de diferentes matérias utilizadas pelas alunas durante 0 Franquismo, planos de colégios, salas de aulas; linhas do tempo com autores fundamentais para a formação educativa como Pestalozzi, Fröebel, Natorp, Montessori, Makarenko, Freinet, Freire; um tutorial da Pedagogia Social e a sua vertente histórica; recuperação de jogos infantis tradicionais dos alunos; fotografias de algumas das dinâmicas de aula e da participação de profissionais; material audiovisual de apresentações efetuadas na aula, de alguns debates grupais e das intervenções de profissionais efetuadas nas aulas; apresentações em power point e prezi dos trabalhos dos alunos e das participações de algumas oradoras; elaboração de projetos de 
intervenção socioeducativa; trabalhos cooperativos sobre o processamento de sinal no sistema cardíaco; recuperação de jogos infantis tradicionais; e trabalhos de fim de licenciatura e fim de mestrado orientados a partir de, e com uma perspetiva histórica e crítico-reflexiva.

Embora seja verdade que o património educativo se centrou principalmente na área formal e curricular, reveste-se de uma importância especial a recuperação do património socioeducativo a partir da construção disciplinar da Pedagogia Social europeia e latino-americana, tendo em vista favorecer processos e experiências que contribuam para o conhecimento a partir de redes de aprendizagem partilhada e comunitária, processos de investigação do quotidiano em educação, assim como experiências de transformação social (CARIDE, e POSE, 2013; ÚCAR, 2016; DEL POZO, 2016).

\section{Conclusões e prospetiva}

As transformações tecnológicas e digitais, juntamente com as novas exigências formativas, de acordo com os parâmetros do Espaço Europeu de Educação Superior, implicam necessariamente uma alteração nas implementações metodológicas e didáticas nas aulas universitárias. Por isso, o PID representou o início de uma experiência formativa, envolvendo e sensibilizando os alunos na aproximação ao estudo histórico e à recuperação de elementos do património socioeducativo, cultural e social das instituições e grupos humanos que desenvolvem a sua ação em diferentes ambientes que fazem parte de processos formativos e de socialização não estritamente unidos ao sistema universitário.

Seguindo Fàbregas, A. e Juanola, R. (201, p. 544).), trata-se de desenvolver

[... ] uma ideia do património pensada para a inclusão e a participação: o processo de patrimonialização efetuado pelos alunos representa uma perspetiva emergente da criação de novos patrimónios e do estabelecimento de processos de patrimonialização em diálogo com as comunidades e de participação real" 
Em consonância com esta implementação, a recuperação de elementos patrimoniais foi efetuada através do desenvolvimento de atividades e processos de investigação-ação em que os alunos se envolveram ativamente.

Este processo foi orientado por objetivos básicos, que permitiram a facilitação do acesso às fontes histórico-educativas para o estudo e investigação em temáticas relacionadas com a História da Educação, a História da Educação das Mulheres, a História da Infância ou o enfoque patrimonial e histórico analisado a partir de outras matérias não históricas; a possibilitação de uma base documental e de recursos para a continuidade na investigação historiográfica-educativa das mulheres e da infância; o início da organização e classificação de fontes histórico-educativas num espaço virtual; e o início de um vínculo entre a procura e a indagação da documentação histórico-educativa, fazendo uso dos recursos tecnológicos virtuais.

O desenvolvimento de uma metodologia que envolveu os alunos, criando interrogativas e inquietações no seu processo formativo, possibilitou a participação em processos iniciais de investigação, de produção de conhecimento, de (re)construção e (re)interpretação, assim como de recuperação, difusão e/ou exposição das suas atividades sobre o património, criando um conjunto de materiais, fontes, recuperação de objetos - entre outros - que fazem parte da memória das instituições.

Os resultados das atividades fazem parte do espaço virtual de aprendizagem, configurado na Web Património, Educação e Sociedade, que criámos como produto final do PID. Este conjunto de experiências mostra-se positivo na medida em que permite a criação de conhecimento, difusão, partilha e interação noutros espaços para além do âmbito temporário limitado das matérias, graças às potencialidades do uso de recursos tecnológicos, que permitem o estabelecimento de vínculos entre História e recuperação do património.

Esta experiência também permitiu que contássemos com contribuições de profissionais que, a partir da sua área socioprofissional, partilharam as suas experiências e mostraram uma ação profissional contextualizada e relacionada com as temáticas de trabalho nas nossas matérias, tanto contribuições a partir do contexto universitário como 
a partir da área da ação social e profissional de ambientes socioculturalmente mais vulneráveis. Este tipo de atividade possibilita o conhecimento de uma diversidade de temáticas, permitindo uma interação direta dos alunos com a realidade profissional de uma área específica, tendo em vista incidir numa transformação da realidade.

Não obstante, a iniciação neste tipo de implementação didática, metodológica, organizativa e de investigação não foi uma tarefa fácil, porque a partir de cada uma das matérias tivemos que pensar e organizar a ação com os alunos, efetuando um seguimento e uma orientação que exigiram tempo, especialmente quando se têm grupos muito numerosos na aula. Das atividades resultantes também foi necessário selecionar as mais relevantes, dar-lhes uma introdução e caracterização para que o espaço virtual de aprendizagem não fosse exclusivamente um repositório de materiais. Também tivemos limitações, em algumas das sessões, de recursos -humanos e materiais - para podermos efetuar gravações das intervenções de profissionais convidados e de algumas dinâmicas de aula, sem nos esquecermos da falta de espaço de armazenamento virtual para alojamento da Página da Internet e todos os materiais carregados na mesma. Os mesmos foram alojados em espaços gratuitos livres.

Mesmo considerando tudo o que precede, o desenvolvimento da experiência de inovação foi positivo na medida em que permitiu o envolvimento dos alunos em processos de investigação e de recuperação do património, considerando a sua própria inquietação na indagação e construção da aprendizagem. Além disso, o espaço virtual de aprendizagem é, em si mesmo, um meio que serve de fundamento para continuarmos a aprofundar, nos cursos académicos sucessivos, este tipo de ações docentes que envolvam os alunos na recuperação de elementos patrimoniais e na construção ativa e participativa do conhecimento.

A experiência docente apresentada está inacabada, na medida em que a Web Património, Educação e Sociedade deverá continuar a ser atualizada de acordo com as contribuições efetuadas pelos alunos nas sucessivas matérias. Também seria necessário dinamizar a Web, introduzindo na mesma espaços dedicados às redes sociais como o Facebook ou o Twitter, espaços que melhoram a interatividade. Embora a proposta de inovação docente tenha sido muito positivamente acolhida pelos alunos, será necessário 
Finalmente, é relevante a difusão da experiência docente efetuada sobre a formação histórica para recuperação do património. Um espaço fundamental será continuar com a participação em eventos científicos, já iniciados tendo em vista difundir e partilhar a experiência (JIMÉNEZ-RAMÍREZ, 2015, 2015b), assim como a difusão em revistas científicas especializadas. Estes canais permitem que se dê a conhecer o trabalho didático efetuado, o que é fundamental para que a implementação seja conhecida noutros contextos universitários, ao mesmo tempo que possibilita o contacto de profissionais que, a partir da sua ação docente e de investigação, estão a trabalhar com elementos de recuperação do património.

\section{Referências}

ALBA PASTOR, Carmen. La Universidad española en el EESS: el profesorado universitario y las TIC en el proceso de convergencia europea. Revista de Educación, n. 337, p. 7-11, 2005. Disponível em: <http://www.revistaeducacion.mec.es/re337/re337_01.pdf>.

ÁlVAREZ DOMínGUEZ, Pablo. El Museo Didáctico Virtual de Patrimonio HistóricoEducativo Andaluz como recurso para la enseñanza de la historia de la educación. In: BERRUEZO, Reyes; CONEJERO, Susana (Coords.). El largo camino hacia una educación inclusiva: la educación especial y social del siglo XIX a nuestros días. Pamplona: Universidad Pública de Navarra, 2009, p. 591-603.

ÁLVAREZ DOMíNGUEZ, Pablo. Museos Virtuales de Pedagogía, enseñanza y educación: hacia una didáctica del patrimonio histórico-educativo. EARI, Educación Artística Revista de Investigación, n. 2, p. 23-27, 2011. Disponível em: $<$ https://dialnet.unirioja.es/descarga/articulo/4356680.pdf >.

AGULLÓ, Carmen; BASCUÑÁN, Javier; PAYÁ, Andrés. Una propuesta sobre el patrimonio histórico educativo valenciano. Diversificar las fuentes, difundir la historia y renovar el discurso pedagógico. Cabás, n. 1, p. 1-22. 2009. Disponível em: <http://revista.muesca.es/index.php/remository?func=fileinfo\&id=18> . 
AGULLÓ, Carmen; PAYÁ, Andrés. La recuperación del patrimonio histórico-educativo valenciano. In: BERRUEZO, Reyes; CONEJERO, Susana (Coords.). El largo camino hacia una educación inclusiva: la educación especial y social del siglo XIX a nuestros días. Pamplona: Universidad Pública de Navarra, 2009, p. 167-198.

BURKE, Peter. Formas de hacer historia. Madrid: Alianza Editorial, 1999.

CANO, John; BARRETO, Carmen; DEL POZO, Francisco José. Competencia Intercultural del estudiantado de educación superior: un estudio en la Universidad del Norte (Barranquilla. Colombia). Encuentros, v. 14, n. 2, p. 159-174, 2016. Disponível em: <http://ojs.uac.edu.co/index.php/encuentros/article/viewFile/734/pdf_41>.

CARREÑO, Miriam. Museología y museografía de la educación. In: ESCOLANO BENITO, Agustín (Ed.). La cultura material de la escuela: en el centenario de la Junta para la ampliación de Estudios, 1907-2007. Berlanga de Duero: Centro Internacional de la Cultura Escolar, 2007, p. 91-110.

CARIDE, José Antonio; POSE, Héctor. Los museos como pedagogía social o necesidad de cambiar la mirada cívica y cultural. Cuestiones Pedagógicas, n. 22, p. 141-160, 2013. Disponível em: <http://institucional.us.es/revistas/cuestiones/22/art_6.pdf >.

DEL POZO, Francisco. José. Pedagogía social escolar en Colombia: el modelo de la Universidad del Norte. Revista Iberoamericana de Educación, n. 70, p. 77-90, 2016. Disponível em: <rieoei.org/rie70a04.pdf >.

DEWEY, John. Experiencia y educación. Buenos Aires: Editorial Losada, 1960.

ESCOLANO BENITO, Agustín. El patrimonio material de la escuela y la historia de la educación. Cuadernos de Historia de la Educación, n. 6, p. 7-9, 2009. Disponível em: <http://sedhe.es/wp-content/uploads/6-El-patrimonio-hist\%C3\%B3rico-educativo-y-laense\%C3\%B1anza-de-la-historia-de-la-educaci\%C3\%B3n.pdf >.

FÀBREGAS, Anna; JUANOLA, Roser. Pescadores, dólmenes y cabras, o cómo hacer de la investigación una realidad participativa. In: Fontal, Olaia; Ballesteros, Paloma; Domingo, María (Coords.). Mirando a Europa: estado de la cuestión y perspectivas de futuro. Madrid: MECD, Ministerio de Economía y Competitividad, OEPE, 2012, p. 537-545.

IDEP . Mapamundi museos pedagógicos. Colombia, 2016. Disponível em: <http://www.idep.edu.co/wp_centrovirtual/?page_id=2874>.

IDEP. Centro Virtual de Memoria en Educación y Pedagogía. Colombia, 2016. Disponível em: <http://www.idep.edu.co/wp_centrovirtual/?page_id=3104>. 
JIMÉNEZ RAMÍREZ, Magdalena. Memory, educational heritage and virtual learning spaces: an experience at the University of Granada. In: ARSLAN, Ali (Ed.). ISCHE 37, Culture an Education. Istanbul: Basky \& Cilt, 2015, p. 424-426.

JIMÉNEZ RAMÍREZ, Magdalena. Recuperación del patrimonio educativo y socio-cultural desde la innovación docente en la Universidad. In: CONGRESO RIAICES, V, Oviedo, 2015. Comunicación presentada. Oviedo, 2015b.

MARTÍ ÚBEDA, Cristina. Potencialidades y usos didácticos del patrimonio virtual en internet para la enseñanza de la historia de la educación. Cuadernos de Historia de la Educación, n. 6, p. 11-39, 2009. Disponível em: <http://sedhe.es/wp-content/uploads/6-Elpatrimonio-hist\%C3\%B3rico-educativo-y-la-ense\%C3\%B1anza-de-la-historia-de-laeducaci\%C3\%B3n.pdf >.

MORENO MARTÍNEZ, Pedro L. La historia de la educación como disciplina y campo de investigación: renovación historiográfica, patrimonio y educación. In: BERRUEZO, Reyes; CONEJERO, Susana (Coords.). El largo camino hacia la educación inclusiva. Aportaciones desde la Historia de la Educación. Pamplona: Universidad Pública de Navarra, 2009, p. 141151, vol. III.

PAYÀ, Andrés; ÁLVAREZ, Pablo. Pensar la educación desde las TIC y la recuperación del patrimonio educativo. In: FONTAL, Olaia; BALLESTEROS, Paloma; DOMINGO, María (Coords.). Mirando a Europa: estado de la cuestión y perspectivas de futuro. Madrid: MECD, Ministerio de Economía y Competitividad, OEPE, 2012, p. 546-554.

RAMOS, Sara; PERICACHO, Francisco Javier. Una propuesta de innovación docente para enseñar historia de la renovación pedagógica en la universidad. Educació i història:

Revista d'història de l'educació, n. 26, pp. 65-88, 2015. Disponível em: <https://dialnet.unirioja.es/servlet/articulo?codigo $=5500884>$.

RUIZ BERRIO, Julio. Pasado, presente y porvenir de los museos de educación. En: ESCOLANO BENITO, Agustín; HERNÁNDEZ DÍAZ, José María (Coords.). La memoria y el deseo: cultura de la escuela y educación deseada. Valencia: Tirant lo Blach, 2002, p. 43-65.

SCHAFFERT, Sandra; HILZENSAUER, Wolf. On the way towards personal learning environments: seven crucial aspects. Elearning Papers, n. 9, p. 1-11, 2008. Disponível em: $<$ http://citeseerx.ist.psu.edu/viewdoc/download?doi=10.1.1.167.4083\&rep=rep1\&type=pdf $>$.

SUÁREZ, Miguel Ángel; CALAF, Roser; SAN FABIÁN, José Luis. Aprender historia através del patrimonio: los casos del Museo del Ferrocarril de Asturias y del Museo de la Inmigración de Cataluña. Revista de Educación, n. 365, p. 38-66, 2014. <DOI: 10.4438/1988592X-RE-2014-365-264>. 
ÚCAR, Xavier. Pedagogías de lo social. Barcelona: UOC, 2016.

UNESCO. Role of museums in education and cultural tourism development. Policy Brief. UNESCO: IFESCCO, 2012. Disponível em:

<http://unesdoc.unesco.org/images/0022/002201/220143E.pdf >.

VIÑAO, Antonio. La Historia de la Educación ante el siglo XXI: tensiones, retos y audiencias. In: CALVO DE LEÓN, Rafael et al. Etnohistoria de la escuela. In: COLOQUIO NACIONAL DE HISTORIA DE LA EDUCACIÓN, XII. Burgos: SEDHE, 2003, p. 1063-1074.

VIÑAO, Antonio. Memoria, patrimonio y educación. Educatio Siglo XXI, v. 28 n. 2, p. 17-42, 2010. Disponível em:

$<$ https://digitum.um.es/xmlui/bitstream/10201/27115/1/Memoria,\%20patrimonio\%20y\%20edu caci\%C3\%B3n.pdf >.

VIÑAO, Antonio. El MUVHE y el CEME como pre-texto. Reflexiones sobre la protección, conservación, estudio y difusión del patrimonio histórico-educativo. In: MORENO, Pedro L.; SEBASTIÁN, Ana (Eds.). Patrimonio y etnografía de la escuela en España y Portugal durante el siglo XX. Murcia: SEPHE/CEME de la Universidad de Murcia, 2012, p. 639-651.

VIÑAO, Antonio. Presentación. Historia y memoria de la educación, n. 1, p. 9-22, 2015. Disponível em: DOI: <http://dx.doi.org/10.5944/hme.1.2015.14109>. Acesso em:

VELASCO, Honorio. La cultura como patrimonio: lo material y lo inmaterial en la cultura. In: ESCOLANO BENITO, Agustín (Coords.). La cultura material de la escuela: en el centenario de la Junta para la Ampliación de Estudios, 1907-2007. Soria: CEINCE, 2007, p. 29-43.

YANES CABRERA, Cristina. El patrimonio educativo intangible: un recurso emergente en la museología educativa. Cadernos de História da Educaçao, n. 6, p. 71-85, 2007a. Diponível em: <http://www.seer.ufu.br/index.php/che/article/view/274>.

YANES CABRERA, Cristina. Aproximación a los fundamentos teóricos y metodológicos de los museos virtuales de historia de la educación: la creación del Museo Didáctico Virtual del Patrimonio Histórico-Educativo. In SÁNCHEZ PASCUA, Felicidad et al. Relaciones internacionales en la historia de la educación: Junta para Ampliación de Estudios e Investigaciones Científicas (1907-2007). Cáceres: SEDHE y Dpto. de Educación de la Universidad de Extremadura, 2007b, p. 567-578. 
Recebido em 31/08/2016 Aprovado em 22/11/2016 